\title{
Academic Publishing in Europe: The Impact of Publishing
}

\author{
20-21 January 2009, Berlin \\ Pre-conference day for younger academic publishers: "Information Competence" \\ 19 January 2009
}

Dr. Svenja Hagenhoff and Dr. Chris Armbruster

\section{Welcome and opening addresses}

Professor Michael Mabe (CEO, International Association of STM Publishers) opened the Fourth International Conference on Academic Publishing in Europe (APE 2009) "The Impact of Publishing". Professor Mabe highlighted that APE 2009 would examine the impact of publishing across institutions such as libraries and repositories, but also with regard to bibliometrics and usage statistics. Moreover, this focus would include the interaction between publishing, technology and new business models, including the Google book settlement.

In a word of greeting Dr. Karl-Peter Winters (Member of the Board of the German Association of Publishers and Booksellers) welcomed all participants on behalf of the Börsenverein. In his opinion, the most important changes of the previous twelve months have been the introduction of Amazon's Kindle, the Google book settlement and the Libreka book finder. These changes again highlighted the continuing impact of the electronic revolution on products, content and users. In this context, he noted that publishers must start rethinking and adjusting their efforts in fighting piracy and illegal sharing. Dr. Winters thanked the organizers and sponsors of APE 2009 and wished the participants interesting proceedings (the speech was read by Arnoud de Kemp).

In his opening keynote, Professor Dr. Georg Winckler (President, European University Association; Rector, University of Vienna, Vienna, Austria) spoke about Universities in the 21st Century. He stated that the university might currently seem like an institution without boundaries or core. Originally, the university had been a community of teachers and students devoted to learning. Later, the French Polytechnique and technical universities in general, introduced a utilitarian element, while the Humboldtian University focussed on research and the search for truth. The American research university dominating 
the 20th century was a hybrid with a strong community, large professional schools and outstanding research programmes. With regard to Europe, Professor Winckler noted that the system had arrived at a critical juncture. In his opinion there often was a reluctance to embrace the requirements of the 21 st century, i.e. open science, institutional autonomy and the pursuit of excellence. Sometimes unwillingness exists to ensure broad and equitable access and to break down the barriers of mobility for knowledge and people. Professor Winckler argued that universities should embrace universal higher education, make junior researchers more independent and accept public accountability.

Professor Winckler sets his hope on open science and, in particular, on rapid and open publication. Researchers should give up their rights to research results in the interests of further research, by providing students with the best and latest knowledge, and by fostering innovation.

In the second keynote Prof. Dr. Rudi Studer (Immediate Past President, Semantic Web Science Association (SWSA) and Karlsruhe Institute of Technology and FZI Research Center for Information Technologies) spoke of The Semantic Web: Enabling Innovative Approaches for Handling Information and Services. He first outlined the idea of the semantic web. Computers can interpret the meaning of data with the help of the semantic web. For this purpose, terms have to be correlated to each other through formal models, resulting in a complex net of terms and relationships that requires a precise ontology in order to generate a semantic knowledge mesh through semantic wikis.

Professor Studer noted that Web 1.0 provided content. Web 2.0 featured the prosumer, the consumer as producer and vice versa. Web 3.0 will enhance content and social networks though semantic data integration and value-added services. It connects people and information much more precisely and extensively, and thus facilitates the sharing and creation of online knowledge at a new level.

News from the European Commission were reported by Dr. Celina Ramjoué (Policy Officer, European Commission Research Directorate-General) on Access to Scientific Information in the Digital Age: European Commission Initiatives. She stressed that the portfolio of the Commission includes policymaking, research funding and capacity building. After a consultation phase (2006-2007), the Commission is now in the phase of implementing decisions made by the European Council and the Commission. As a research funder (FP7 budget over $€ 50 \mathrm{bn}$ ), the Commission is engaging in a number of experiments with regard to Open Access. Among these are the European Research Council OA mandate for publications and data; the reimbursement of OA publication charges in FP7; the OA pilot in FP7; the funding of a scientific information repository. The Commission aims at drawing conclusions and at developing policy further in time for FP 8 (from 2014).

The session Information Discovery and Access: Repositories, Infrastructures, Libraries, How Everything Comes Together, was chaired by Dr. Salvatore Mele (CERN, Open Access Section Project Leader/SCOAP3 - Interim Project Manager, Geneva, Switzerland).

Dr. Ralf Schimmer (Max Planck Digital Library, Munich) presented The European Landscape of Licensing, beyond Content. He emphasised three drivers of licensing: technology, open access and users. Users, in particular, want more than just access and they are doing more than just reading. For example, scientific information is nowadays mined and enhanced to develop new research questions. Dr. Schimmer pointed out that while the Max Planck Society supports OA across the board, its core support is directed towards OA publishing. The MPDL has calculated that a complete switch to OA publishing would be cost neutral for the MPS, even though the research output of the MPS is quite considerable.

Dr. Schimmer noted that this calculation holds valid even for average publication charges of $€ 3000$ per article (the current maximum). The MPDL does not expect any exceptional transition costs because of its unified budget for subscription and publication costs. Dr. Schimmer concluded by pointing out the 
ongoing support of the MPDL for OA publishing, for example, by supporting the Sponsoring Consortium for Open Access Publishing in Particle Physics and the participation in a Study of Open Access Publishing, a support action for the European Commission.

Travis Brooks (Stanford Linear Accelerator Center, Stanford, CA, USA) reported on Organizing a Research Community with SPIRES: Where Repositories, Scientists and Publishers meet. He explained that SLAC is a community organizer for the 20,000-30,000 researchers in High Energy Physics. 50\% are theoreticians, organized in small global collaborations, producing $80 \%$ of the published papers. Experimental researchers are organized in large global collaborations accounting for the remaining 50\% and producing $20 \%$ of the papers, mainly reporting results and techniques.

Mr. Brooks noted that for HEP researchers journal publications are too slow and institutional repositories do not represent a serious source. By contrast, SPIRES (Stanford Public Information Retrieval System) is a one-stop shop simplifying the landscape for the research by providing nearly $100 \%$ open access to scientific information, mainly through pre-prints (but with links to full text from all known sources). SPIRES attracts 25,000 searches a day. In a joint project with CERN and others, SLAC is migrating SPIRES to INSPIRE, a service that will remove boundaries between research fields, repositories and the researchers and curators. At this intersection a future for scholarly communication is being forged.

Dr. Carlos Morais Pires (Head of Sector - Scientific Data Infrastructures, European Commission, INFSO F3) reported on European Commission: e-Infrastructure for Europe - From Networks and Grids to Repositories and Scientific Data. He acknowledged that capacity-building is based on parsimony, a broad user base and excellent services. The EU supports connectivity to enhance the federation and sharing of data. Due to the fact that e-infrastructures change the way scientists work, and scientists are looking for new and different infrastructures, the primary challenges are to deal with the new 'bigness' of files, numbers and distances; to secure permanent access to born-digital content; and to facilitate crossdisciplinary uses of e-infrastructures. e-Infrastructures hold scientific information. Dr. Pires emphasised that the speed of information transfer or access, the volume available and the value of the content are essential.

The session Usage and Impact was chaired by Mayur Amin (Senior Vice President, Research and Academic Relations, Elsevier, Oxford, UK).

Ian Rowlands (CIBER, University College London, London, UK) spoke about Electronic Journals: Modelling Journal Spend, Use and Research Outcomes. He reported on a strong correlation between journal usage and research outcomes. By tracking behaviour at selected institutions it can be shown that a larger number of downloads correlate with more publications or that active researchers are more efficient in their searches. Generally, a correlation can be noticed in the sense that the top universities and departments are also great users of journals. On the whole, Mr. Rowlands noted that it can be observed that the easier the use of journals and other academic resources, the higher the usage. Researchers clearly prefer a one-stop shop solution and will begin their searches and queries from a generic search engine (rather than a specific portal).

Dr. Henk F. Moed (Centre for Science and Technology Studies (CWTS), Leiden University, Leiden, The Netherlands) examined Metrics-Based Research Evaluation - what have we learnt so far? $\mathrm{He}$ pointed out that most frequent shortcuts used in research evaluation lead to inaccurate assessments. The Journal Impact Factor does not predict the impact of any specific publication (or researcher). Moreover, there is conclusive evidence that the JIF is being manipulated by the various actors involved. The $\mathrm{H}$-index is misleading because of the fact that it neither captures the full impact nor the actual distribution of citations. Dr. Moed proposed the propagation of normalised citation impact indicators accounting for the 
research field, the age of the publication and the type of paper as an alternative. Conducted bottom-up, beginning with a list of researchers; or top-down, by counting the output of an institution, this procedure will lead to a valid research assessment, particularly if combined with intelligent peer review.

Richard Gedye (Research Director, Journals Division, Oxford University Press, Oxford, UK) presented Usage Factor and PIRUS - a Move towards more sophisticated, granular and comprehensive Usage Metrics. He reported that a comparable and comprehensive usage factor for measuring reach, and as a counterweight to the impact factor, would be widely supported by librarians and researchers. Particular issues, besides combating gaming, relate to the question of how to count usage across multiple sites as well as of print issues (as print access is still relevant). While there has been some discussion on creating a journal usage factor, the project PIRUS (Publisher and Institutional Repository Usage Statistics) aims at generating usage reports at the item level. As online usage is becoming an accepted measure of article and journal value, the challenge is to measure the usage of the same article at different source locations like the journal's website, the author's web site or any repository. PIRUS therefore intends to develop a global standard for individual journal articles, wherever hosted.

At the close of the first day, Dr. Sven Fund (CEO, Walter de Gruyter, Berlin, Germany) introduced as a special guest Jil Cousins (Director, The European Library and EDL Foundation, The Hague, The Netherlands). Jil Cousins presented Europeana, a virtual European library as a collection of the European cultural and scientific heritage (www.europeana.eu). Europeana has delivered proof-of-concept. Jil Cousin said user demand was very high and was initially overwhelming. Its multilingual portal holds much audio and audiovisual content, but also objects like images, texts, maps, drawings, paintings and photographs. The initial project was funded by the European Commission under the eContentPlus programme. The EDL is developing its business model to combine structural funding with revenue generation. A notable aspect was the fact that both the front office (e.g., advertising, merchandise) and the back office (e.g., semantics, development) are to generate revenue.

The second conference day commenced with two parallel panels.

The session named "The Impact of Technology" was chaired by Anthony Watkinson (University College London, London, UK).

Sebastjan Mislej (Jozef Stefan Institute, Ljubljana, Slovenia) presented the project videolectures.net, a video lectures online knowledge repository with freely accessible scientific content, presenting the opportunity to record or upload all kinds of scientific events like lectures, conferences, summer schools or workshops. All material is selected and classified by means of an editorial process.

Dr. Hans Pfeiffenberger (Helmholtz Association, Alfred-Wegener-Institute, Bremerhaven, Germany) reported on Publishing Data. He focused on data from polar research and oceanography. He explained that there are two types of data: (1) Peta scale data that may be handled in industrial fashion and collated into one super-dataset, comparable to a book holding the work of a lifetime. (2) Mega scale data composed of large numbers of heterogeneous datasets which is processed as in a manufacture communicated on demand through mail or via ftp-server and is comparable to the letter from scholar to scholar. Yet, there is almost no possibility to handle the bulk of Giga to Terra scale data. A system of academic journals comparable to journals for textual information is needed for this kind of data. Next, Dr. Pfeiffenberger introduced the ESSDD journal (Earth System Science Data) which was published by Copernicus and aims at the publication of articles on original research datasets. The review guidelines demand originality, significance and data quality. In his final remarks, Dr. Pfeiffenberger noted some challenges faced when publishing data, including long-term preservation and access to data for reuse and reproduction. 
Kevin Cohn (Director of Product Development and Client Services, Atypon Systems, Inc., Santa Clara, CA, USA) focused on The Serendipity of Online: Information Discovery Amidst Information Overload. Based on an example of Barnes and Nobles he pointed out the benefits of physically accessible media like books in a bookstore allowing the customer to browse all content and to flip through single pages of a book enabling him to find content he otherwise could not find (serendipity). Dr. Cohn posed the question of what would happen to those serendipities in case of online content. In his opinion, services are needed in order to substitute the opportunities physically accessible media offer, because of fundamental differences in the paths that users take to access content. Services include search inside, read first page, or collaborative filtering offered, for example, at Amazon's web page. This means that serendipity can exist online, but that it has to be guided by technological innovations. Additionally, more algorithms have to be employed to assist information discovery. Interfaces will continue to evolve and will rely more heavily on visual cues.

John Gardner (President, ViewPlus Technologies, Corvallis, OR, USA) and Robert Kelly (Director, Journal Information Systems, The American Physical Society, Ridge, NY, USA) spoke on the topic The Future is Near: Universally Usable Mainstream on-Line Publishing and presented the IVEO ${ }^{\circledR}$ Handson-Learning-System, which allows the combination of vision, sound, and touch. They explained that the system makes images like diagrams and graphs accessible to visually handicapped people. For this purpose the system creates images being rendered in tactile or audio form enabling print-disabled persons to feel the image via a tactile touchpad or after printing it out with an embossing printer. The system also reads values of data points and labels when touching them.

Dr. Thomas Kalisch (German Central Library for the Blind (DZB), Leipzig, Germany) gave some information on the Daisy 2009 conference taking place in Leipzig, Germany, September 21st-27th 2009 (http://www.daisy2009.de). Daisy stands for Digital Accessible Information System (www.daisy.org), an XML-based format for digital talking books, allowing users to navigate audio content from chapter to chapter or page to page or even from footnote to footnote.

The Round Table Partners in Preservation. Who Is Doing What and How in the Field of Long-Term Preservation of Digital Publications was chaired by Els van Eijck van Heslinga (European Alliance for Permanent Access of the Records of Science, National Library of the Netherlands, The Hague, The Netherlands). It was organised to create awareness of the problems of long-term preservation of digital scholarly publications, particularly of the accessibility and understandability of source and presentation files. Questions of responsibility and coordination in preservation were in focus, highlighted through a number of EU projects. The Round Table participants were asked to give a statement. Wouter Schallier (European Association for Research Libraries) said that "libraries and cultural institutions are trusted archives by their mission, publishers are not". Joep Verheggen (Elsevier) responded that publishers have a clear responsibility to their journal articles to assure permanent preservation of the authors' work. The trick is to find the right third parties to partner with. Eileen Fenton (Portico, NY, USA) opined that "successful long-term digital preservation requires multiple preservation methods and tools developed through an international R\&D effort", and Marcel Ras (Head, e-Depot National Library of The Netherlands) seconded that "in order to deal with the enormous challenges of long-term preservation of digital publications, a world wide coordinated approach is an absolute necessity".

In the subsequent discussion, the potential for cooperation and conflict between publishers and libraries was debated, often criticising and defending each institution in turn. However, the discussion also resulted in important insights: Firstly, the issue of responsibility has a legal and an intellectual dimension. Difficult but important decisions have to be made as to what is preserved, while the notion of the legal deposit has to be further elaborated for born-digital content. Secondly, the difficulties of 
international cooperation are real, requiring persistence in the pursuit of sustainable technical and organisational solutions. Finally, it was pointed out that the accessibility and understandability of preserved items have to be supplemented by a third principle: findability. The value of preservation is to provide future generations of scholars with better opportunities to retrieve publications.

Two more parallel sessions followed.

The Road Ahead was chaired by Dr. Einar Fredriksson (Director, IOS Press, Amsterdam, The Netherlands).

The first presenter was Wim van der Stelt (Executive Vice President Business Development, Springer). In his presentation named New Business Models: Defense or Nä̈veté? he talked about Springer's approaches within the online world. In a first step he asked whether the world going online was a threat for publishers. He clarified that researchers use different discovery tools for scientific information, depending on the information task. For so called background research (new area research), the preferred tool is Google or Google Scholar. For focused research (literature review for establishing research base) or bibliographic searches (finding a reference), A\&I databases such as PubMed or SciFinder are applied. For keeping up-to-date (browsing current literature), library portals are preferred. Mr. Van der Stelt pointed out that the SpringerLink acts as a repository for Springer's published research, but not as a starting point of scientific information tasks. Instead, the Google Book Search program is a significant marketing channel and attracts more book views than Springer.com. SpringerLink, however, is among the top content sites in the world. Then Mr. van der Stelt talked about the future of books and asked whether e-Books pose a threat to publishers. He pointed out that e-Book Collection includes all Springer books starting from 2005, and that with about 30,000 e-Books on the SpringerLink platform, Springer is the number one in the STM e-Book market. At the US market Springer is now running a pilot project named Springer MyCopy, allowing users to get a print book directly from the e-Book collection. Concerning the future of journals, Wim van der Stelt focussed on Springers Open Choice as a reaction to the Open Access Movement. He said that $\$ 3,000$ or $€ 2,000$ per article are charged for that option.

Dirk Lens (Member of the Executive Board, Swets, Lisse, The Netherlands) spoke about Multiplication of Impact through Simplification. He presented the subscription agency Swets as an intermediary between subscribers and publishers, aiming at reducing the commercial and administrative workload of managing subscriptions. As an effect, the supply chain efficiency will improve and the fulfilment capabilities will be enhanced. He introduced the main functionalities of the SwetsWise product portfolio which includes activities to acquire, access and manage subscriptions. Especially as electronic submissions become more and more important these days, $94 \%$ of publishers rate the service of subscription agents to be of equal or even greater importance for electronic subscriptions than that of print media. Swets will also help publishers to enter new markets by the Swets Gateway, a direct sales channel focusing on the growth markets across the Asia Pacific region.

Dr. Paul Evans (Senior Vice President, International Publishing Development, Elsevier Science, Amsterdam, The Netherlands) talked about The New Deal - Freedoms, Experiments, Sustainability - The Road Ahead. He emphasized innovation and noted that the stakeholders of the research process had to demonstrate the value of research and innovation in times of financial crisis. Dr. Evans has surveyed innovation activities at Elsevier since the 1990s, in the STM industries more generally. He reported that the Elsevier editorial system ScienceDirect has reduced reviewing times by 50\%; and that the final publishing decision just needs 17 weeks instead of 26. Another example for innovation was the tool illumin8, designed for corporate R\&D professionals. It allows searches across billions of web pages, premium scientific articles, and patents and can also find organizations, products, experts, approaches or technical landscapes. The speaker focused on the publishers' responsibility to have an influence on governments 
and to avoid short-termism. Instead, long-term problems such as energy or environment should be in the focus of interest for the benefit of succeeding generations. The publishing industry should also prevent edicts on where to publish. The government should not limit academic freedom. Finally, Dr. Evans came to the conclusion that innovations in the publishing world need a mixed economy of different players working together and developing new tools and services to promote research. The publishing world has to work within the research community and has to play its role in securing overall support from governments.

Dr. Michael Jubb (Director, Research Information Network (RIN), London, UK) asked Forward, but in What Direction? He stressed that key stakeholders in the publishing industry consisted of researchers as creators, disseminators and users; research funders, research institutions, publishers, ICT providers and libraries. He noted that the volume of research has increased and that more of it is done jointly. Researchers are producers and consumers in one person, but they do not necessarily share the same interests. Dr. Jubb reported that the government invests in research because of the positive impact on society, and that governments want to maximise that impact. Yet the costs of research have increased, and cost-effectiveness will become a dominant theme.

Dr. Jubb outlined challenges for the future with respect to content, service, and skills. He noted that the creators and consumers of scholarly papers are the drivers of the scholarly system, but that less knowledge exists on how information resources and services are used. The users themselves do not understand the digital information system, but they want to have quick access and convenient handling. They both want to have quality-assured and non-quality-assured content. He stressed that there is an increasing demand for assessment and evaluation services. Concerning sustainability, he mentioned that there is a growing interest in the overall costs of the scholarly communications process, and in the (cost-) efficiency of the research process as a whole. While Government and funding agencies support for "gold" OA policies universities and research institutions support is the "green" OA. Overall, a concentration of resources and services has to be observed, including overlaps between different types of providers such as researchers and research institutions, libraries and library consortia, publishers and aggregators or search and navigation services.

A Panel: Open Books was convened, chaired by Dr. Michael Kaiser (Editor in Chief, perspectivia.net). The panel was organised around two questions: "What do users expect now and in five years?" and, "How might Open Access publishing models for books change the scholarly communication and then change the market?"

Eelco Ferwerda (Coordinator of Open Access Publishing in European Networks; Publisher at Amsterdam University Press, Amsterdam, The Netherlands) observed that users increasingly expect not only to find, but also to access books online (e.g., Google Book Search) in order to peruse them. Moreover, books may be enhanced by research data and updates, or, more radically, the writing of books may be made more simple by using a wiki, bringing the text together with sources and data and allowing elearning applications. Once users recognise the value, they will demand these features, and open books may provide the solution. Mr. Ferwerda noted that the basic publishing model for open books is hybrid: the basic online edition is free, whereas the printed edition is sold. Moreover, costs for the online edition would be recuperated through a publication charge. OAPEN is currently in the process of helping publishers to develop a common approach for setting up an online library and consulting with a wide variety of stakeholders on the future of open books.

Dr. Frances Pinter (Publisher of Bloomsbury Academic, London, UK) began by pointing out that the academic book publishers were possibly losing their traditional role as gatekeepers, bankers and brand managers, because books are beginning to exist online in multiple versions and formats. She suggested 
that it could be worthwhile considering the inversion of the current online model by offering (book) content free and by charging for services and activities adding value (e.g., printing, review, evaluation). Bloomsbury Academic, launched in autumn 2008, uses a Creative Commons non-commercial license to structure its non-exclusive contract with authors and users. The model assumes that revenue is generated by adding value to the publishing process; a value funded (or paid for) by third parties.

Barbara Kalumenos (Director of Public Affairs, STM) highlighted that books are available in many formats, such as monographs, reference works or textbooks. The same user might consult a variety of formats on a particular topic; some formats, however, are also geared towards particular user groups (e.g., students). Ms. Kalumenos stressed that STM currently has no defined agenda on the question of open books. At present, STM and its members are engaged in studying the costs and benefits of having journals in open access, either by open access publishing or by archiving the author's final manuscript (publisher deposit or self-archiving of manuscripts). On the latter issue, the EU is co-funding a study on Publishing and the Ecology of European Research. First results may be expected in late 2009.

The subsequent discussion highlighted that, except for users, technology and research funders are the two other important drivers. It was said that considering the fact that online reading becomes more convenient and reading devices continue to be successful, technological progress may provide strong incentives for open access to digital books. This trend may be reinforced by research funders demanding open access to research results published in books and covering the resulting publication charges. In conclusion it was emphasised that publishers bring value to the process by insisting on peer and commercial review, corresponding to an assessment of potential impact and usage.

The session Google, Publishing and Electronic Libraries: Visions, Challenges, Opportunities, Consequences was chaired by Mark Seeley (Senior Vice President and General Counsel, Elsevier, NY, USA).

At the beginning of his speech Dr. Daniel J. Clancy (Engineering Director, Google Inc., CA, USA) reported on the aims of Google Book Search (GBS), e.g. making a book as easy to find as a webpage and enhancing the user's ability to access and read books. Also, an opportunity was to be created for authors and publishers to make their books available. According to Dr. Clancy, Google Book Search has two sources. The first is the partner program. Google Book Search enables publishing houses and authors to transmit the contents of the books for the integration in GBS. The second is the library project. GBS has scanned the collections of partner libraries. For books protected by copyright, search results are limited to metadata and selected (random) text passages. Books out-of-copyright may be read online in full length or downloaded. Dr. Clancy stated that in a typical US university library collection about $25 \%$ of the collection was printed before 1923 , while $75 \%$ was published since then. However, only a quarter of these books are in print, the rest being out of print or orphaned. GBS principally makes all these books available, giving new life to old material.

Jan F. Constantine (General Counsel, Authors Guild, NY, USA) elaborated on the settlement between Google and the Authors Guild, which is expected to be legally binding for the United States. An important outcome is the not-for-profit Book Rights Registry, through which rights-holders can assert their rights to books scanned by Google. GBS now offers: (1) Books protected by copyright that can partially be pre-viewed and bought or borrowed (from your library); (2) Books protected by copyright that are out of print and made accessible through preprint or buying options in case the rights-holder does not deactivate these options. (3) Books protected by copyright that can be read, downloaded and printed.

Overall, GBS will offer five access models: (a) online preview; (b) online consumption by buying (e.g., PDF) or a pay-per-view scheme; (c) an institutional subscription to works under copyright but 
out of print; (d) public access terminal in local libraries; and (e) new models like print-on-demand. International books in the US are included in the settlement, but the settlement as a whole does not apply outside the US.

The Closing Panel was chaired by Dr. Herman P. Spruijt (President, International Publishers Association (IPA), Geneva, Switzerland). The panellists were: Prof. Dr. Claudia Lux (President, International Federation of Library Associations and Institutions (IFLA)), Dr. Daniel J. Clancy (Google Inc.), Jan F. Constantine (Authors Guild). Mark Seeley (Senior Vice President and General Counsel, Elsevier, NY, USA), Prof. Dr. Wulf von Lucius (Lucius and Lucius Verlagsgesellschaft mbH).

Firstly, the panellists gave their impressions concerning Google Book Search and the Settlement Agreement. It was pointed out as positive that Google Book Search helps users to discover books, and assists publishers to re-commercialize sleeping rights. From the librarian's point of view, it should be a benefit that libraries now have access to a big collection of books. The possibility of right holders to opt out was also welcomed. A more critical aspect is the fact that from the European publishers' point of view the settlement is very complex. It was also mentioned that Google has always pointed out not to sell books. However, this is actually being done. It was stressed that a strict distinction has to be made between "search" and "find" activities on the one hand and selling and fees on the other. The risk is that Google Book Search will dominate the book market ("free for all or fee for all?"). It was also discussed whether to give up copyright, because it is of no use any longer. Especially, if publishers have books being out of print, the question should arise why they do not put them out of copyright to make them available via alternative distribution channels. One panellist also wondered about the great harmony that seems to have been settled between Google, authors, publishers and librarians.

Finally, Herman P. Spruijt desired a sharper focus on the authors' point of view for APE 2010, because they are very important players within the system of scholarly communication.

\section{Berlin, Göttingen, February 2009}

For correspondence: info@ape2009.eu

Most presentations (in PowerPoint format) can be found on the website: www.ape2009.eu

Full Proceedings of the APE 2009 Conference will be published as a special OA issue of the journal "Information Services \& Use" (IOS Press, Amsterdam, The Netherlands)

The Fifth APE Conference will be held 19-20 January 2010 in the Berlin Brandenburg Academy of Sciences

Correspondence: info@digiprimo.com

APE Conferences are organized by digiprimo GmbH \& Co.KG, a company registered at the District Court of Mannheim. Correspondence address: P.O. Box 103305, D-69023 Heidelberg, Germany. 